\title{
Individualization of risk factors for postoperative complication after lung cancer surgery: a retrospective study
}

\author{
Nozomu Motono*, Masahito Ishikawa, Shun Iwai, Yoshihito lijima, Katsuo Usuda and Hidetaka Uramoto
}

\begin{abstract}
Background: The risk factors for postoperative complications after pulmonary resection in patients with non-small cell lung cancer (NSCLC) have not been elucidated.

Methods: Clinical data of 956 patients with NSCLC were analyzed. Patient factors such as sex, age, comorbidities, smoking history, respiratory function, and the lobe involved in lung cancer and operative factors such as operative approach and operative procedures were collected and analyzed.

Results: Male sex (odds ratio [OR]: 1.73, 95\% confidence interval [CI]: 1.09-2.75, $p=0.01$ ), coexistence of asthma (OR $2.68,95 \% \mathrm{Cl} 1.19-6.02, \mathrm{p}=0.01)$, low percentage of forced expiratory volume in $1 \mathrm{~s}(\mathrm{FEV})(\mathrm{OR} 1.41,95 \% \mathrm{Cl} 1.02-1.95$, $p=0.03)$, and lobectomy or greater resection (OR 2.47, 95\% Cl 1.66-3.68, $p<0.01)$ were identified as significant risk factors for postoperative complications. Male sex (OR 1.98; 95\% Cl 1.03-3.81, $p=0.03$ ) and complete video-assisted thoracic surgery and robot-assisted thoracic surgery (OR 1.64; $95 \% \mathrm{Cl} 1.09-2.45 ; \mathrm{p}=0.01)$ were identified as significant risk factors for postoperative air leakage. Coexistence of asthma (OR 9.97; $95 \% \mathrm{Cl} 3.66-27.38 ; \mathrm{p}<0.01$ ) was identified as a significant risk factor for postoperative atelectasis or pneumonia. Lobectomy or greater resection (OR $19.71 ; 95 \% \mathrm{Cl}$ 2.70-143.57; $p<0.01$ ) was identified as a significant risk factor for postoperative arrhythmia.
\end{abstract}

Conclusion: Male sex, coexistence of asthma, low percentage of $\mathrm{FEV}_{1}$, and operative procedure were significant risk factors for postoperative complications. Furthermore, risk factors varied according to postoperative complications.

Keywords: Postoperative complication, Risk factor, Non-small cell lung cancer, Surgery

\section{Introduction}

Lung cancer is the leading cause of cancer-related mortality worldwide [1]. The incidence of postoperative complications associated with pulmonary resection for non-small cell lung cancer (NSCLC) was reported to be $9-37 \%$ [2-4]. Furthermore, the incidence of postoperative complications associated with lobectomy was $10-50 \%$ and it was higher in the elderly [5]. Several postoperative complications might occur after pulmonary

*Correspondence: motono@kanazawa-med.ac.jp

Department of Thoracic Surgery, Kanazawa Medical University, 1-1

Daigaku, Uchinada, Ishikawa 920-0293, Japan resection. Air leakage, pneumonia, atelectasis, and arrhythmia are considered common complications. The incidence of postoperative pulmonary complications after pulmonary resection was reported to be $6-30 \%$. Age, smoking history, and chronic obstructive pulmonary disease are considered significant risk factors for postoperative pulmonary complications [6-10].

Video-assisted thoracic surgery (VATS) for patients with NSCLC has been widely adopted and various studies have reported the advantages of the VATS approach [11-14]. These reports have shown that VATS is associated with less pain, shorter hospital stay, less reduction in the inflammatory immune response, and maintenance of 
postoperative respiratory function when compared with thoracotomy. However, the relationship between postoperative complications and operative approaches such as VATS in NSCLC patients who have undergone pulmonary resection has not been elucidated.

In the present study, we retrospectively evaluated the risk factors for postoperative complication after pulmonary resection in NCSLC patients, and individualized the risk factors each postoperative complication.

\section{Materials and methods \\ Patients}

1129 NSCLC patients who underwent pulmonary resection at Kanazawa Medical University between January 2002 and March 2020 were identified. Among these, 173 patients were lost to follow-up, and then, 956 patients were enrolled in the present retrospective study (Fig. 1).

Data including clinical factors such as gender, age, comorbidities, smoking history, respiratory function, and the lobe involved in lung cancer were collected. The average life expectancy of Japanese people is increasing, and since 75 years old or older is defined as the late-stage elderly, it is divided by 75 years old. The comorbidity was evaluated by the Charlson comorbidity index [15]. Furthermore, comorbidities were divided into five categories: interstitial lung disease, malignant disease, asthma, arrhythmia, and angina pectoris. Smoking history was assessed using the Brinkman index, which is calculated by multiplying the number of cigarettes smoked per day by the number of years the subject has been smoking [16]. Respiratory function parameters such as percentpredicted vital capacity (\%VC) and forced expiratory volume in $1 \mathrm{~s}$ as a percentage of forced vital capacity $\left(\mathrm{FEV}_{1} \%\right)$ were collected. In Japan, FEV1.0 of less than $70 \%$ is defined as obstructive ventilatory impairment.

\section{Operative factors}

The operative approach was divided into four categories: complete VATS (C-VATS, surgery performed only to provide a monitoring view, wound length less than $8 \mathrm{~cm}$ ), hybrid VATS (H-VATS, surgery combined with direct vision without rib spreading, wound length more than $8 \mathrm{~cm}$ ), robot-assisted thoracic surgery (RATS),

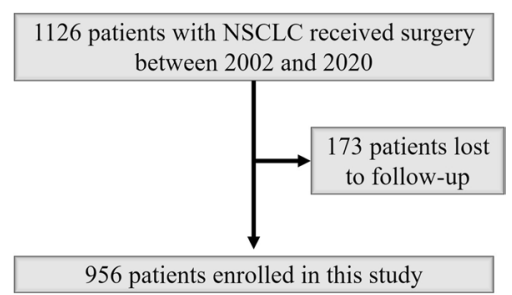

Fig. 1 Flowchart of this study and thoracotomy. The operative procedure was divided into eight categories: wedge resection, segmentectomy, lobectomy, sleeve lobectomy, lobectomy combined with segmentectomy, lobectomy combined with chest wall resection, bi-lobectomy, and pneumonectomy.

\section{Postoperative complications}

Postoperative complications were categorized into five grades according to the Clavien-Dindo classification system [17]. The Clavien-Dindo classification was established in 1992. It is a simple and feasible grading system for all types of postoperative complications [18]. In 2004, it was modified to allow for the grading of life-threatening complications and long-term disability caused by a complication [19]. This revised version has defined five grades of severity with subgrades (grade I, II, IIIa, IIIb, IVa, IVb, and V) and the suffix "d" (for "disability") is used to denote any postoperative impairment. This modified version of the Clavien-Dindo classification has been widely used in clinical practice. Major postoperative complications were defined as follow; air leakage which categorized grade IIIa or more, arrhythmia which categorized grade II or more, atelectasis which categorized grade IIIa or more, pneumonia which categorized grade II or more, chylothorax which categorized grade IIIa or more, cerebral infarction which categorized grade II or more, and bronchopleural fistula which categorized grade IIIa or more. Minor but serious postoperative complications were defined as the postoperative complications which categorized grade IIIb or more except for the major postoperative complications. We also divided the postoperative complications into three categories for multivariate analysis of risk factors: air leakage, atelectasis or pneumonia, and arrhythmia.

\section{Statistical analyses}

Pearson's chi-squared test of independence was used to compare the frequencies of variables. The risk factors related to postoperative complications were analyzed using logistic regression analysis. All statistical analyses were two-sided and statistical significance was set at $\mathrm{p}<0.05$. Statistical analyses were conducted using the JMP software program version 13.2 (SAS Institute Inc., Cary, NC, USA).

The present study was conducted in accordance with the principles of the Declaration of Helsinki. The Institutional Review Boards of Kanazawa Medical University approved the protocol (approval number: I392) and written informed consent was obtained from all patients. 


\section{Results}

\section{Patient characteristics}

The clinical characteristics of the 956 patients are listed in Table 1. Among these, 585 were men and the median age was 69.7 years. The median Brinkman index was 540. Altogether, 540 patients had comorbidities including 135 patients with hypertension, 137 with diabetes mellitus, 22 with interstitial lung disease, 161 with malignant disease (19 with colon cancer, 8 with rectal cancer, 50 with gastric cancer, 16 with breast cancer, 17 with prostate cancer, 12 with bladder cancer, 4 with gallbladder cancer, 14 with thyroid cancer, 4 with renal cancer, 5 with laryngeal cancer, 10 with pharyngeal cancer, and 3 with tongue cancer), 28 with asthma, 26 with arrhythmia (23 with atrial fibrillation, 2 with paroxysmal supraventricular tachycardia, and 1 with atrioventricular block), and 70 with angina pectoris. The median \%VC was $100.1 \%$ and the median $\mathrm{FEV}_{1} \%$ was $73.7 \%$. The pulmonary lobes resected for NSCLC included right upper lobe in 289 patients, right middle lobe in 58, right lower lobe in 231, left upper lobe in 220 , and left lower lobe in 158 patients.

\section{Operative factors}

C-VATS was performed in 329 patients, H-VATS in 509 patients, RATS in 12 patients, and thoracotomy in 106 patients. Wedge resection was performed in 173 patients, segmentectomy in 74 , lobectomy in 643 , sleeve lobectomy in 6 , lobectomy combined with segmentectomy in 3 , lobectomy combined with chest wall resection in 12 , bilobectomy in 18, and pneumonectomy in 27 patients.

\section{Postoperative complications}

Postoperative complications were observed in 257 patients $(26.8 \%)$. Clavien-Dindo grade I complications were noted in 1 patient, grade II in 101, grade IIIa in 146, and grade IIIb in 9 patients. Major postoperative complications included air leakage in 122 patients (Clavian-Dindo grade II in 6, IIIa in 105 and IIIb in 1), arrhythmia in 58 (atrial fibrillation in 55 patients, paroxysmal supraventricular tachycardia in 2 patients, and ventricular tachycardia in 1 patient, grade II in 56, IIIa in 2), atelectasis in 26 (grade II in 1 and IIIa in 25), pneumonia in 21 (grade II in 20 and IIIa in 1), chylothorax in 6, cerebral infarction in 5 , and bronchopleural fistula in 3 patients. Minor but serious postoperative complications included postoperative bleeding in 3 patients, right middle lobe torsion in 1 patient, and right middle lobe congestion in 1 patient. All these complications were resolved by surgery. Although postoperative death was observed in 1 case,
Table 1 Patient characteristics

\begin{tabular}{|c|c|}
\hline Gender (male/female) & $585 / 371$ \\
\hline Age, median (range) & $69.7(22-92)$ \\
\hline Comorbidity & $550(57.5 \%)$ \\
\hline Interstitial lung disease (\%) & $22(2.3 \%)$ \\
\hline Malignancy (\%) & $161(16.8 \%)$ \\
\hline Diabetes mellitus (\%) & $136(14.2 \%)$ \\
\hline Asthma (\%) & $28(2.9 \%)$ \\
\hline Arrhythmia (\%) & $26(2.7 \%)$ \\
\hline Angina pectoris (\%) & $70(7.3 \%)$ \\
\hline $\begin{array}{l}\text { Charlson comorbidity index } \\
(0 / 1 / 2 / 3 / 4 / 5 / 6 / 7)\end{array}$ & $539 / 201 / 152 / 47 / 13 / 3 / 1 / 1$ \\
\hline Smoking index, median (range) & $540(0-3600)$ \\
\hline \%VC, median (range) & $100.1(51.5-177.7)$ \\
\hline $\mathrm{FEV}_{1} \%$, median (range) & $73.7(30.5-99.4)$ \\
\hline \multicolumn{2}{|l|}{ Lobe of lung cancer } \\
\hline RU/RM/RL/LU/LL & 289/58/231/220/158 \\
\hline \multicolumn{2}{|l|}{ Operative approach } \\
\hline RATS/C-VATS/H-VATS/Open & $12 / 329 / 509 / 106$ \\
\hline \multicolumn{2}{|l|}{ Operative procedure } \\
\hline $\begin{array}{l}\text { Part/Seg/Lob/Sleeve Lob/Lob + Seg/ } \\
\text { Lob + CW/Bilob/Pneumo }\end{array}$ & $173 / 74 / 643 / 6 / 3 / 12 / 18 / 27$ \\
\hline Stage (IA/IB/IIA/IB/IIIA/IIB/IV/y|A/y\|A) & $563 / 167 / 60 / 81 / 70 / 5 / 4 / 5 / 1$ \\
\hline $\begin{array}{l}\text { Histology (Ad/Sq/LCNEC/AdSq/Pleo/Large/ } \\
\text { Carci) }\end{array}$ & 726/180/19/11/9/4/7 \\
\hline Postoperative complication & $257(26.8 \%)$ \\
\hline Clavien-Dindo grade (0/1/2/3a/3b) & 699/1/101/146/9 \\
\hline Air leakage (\%) & $112(11.7 \%)$ \\
\hline Arrhythmia (\%) & $58(6.1 \%)$ \\
\hline Atelectasis (\%) & $26(2.7 \%)$ \\
\hline Pneumonia (\%) & $21(2.2 \%)$ \\
\hline Chylothorax & $6(0.6 \%)$ \\
\hline Cerebral infarction (\%) & $5(0.5 \%)$ \\
\hline Bronchopleural fistula & $3(0.3 \%)$ \\
\hline 30-day mortality (\%) & $1(0.1 \%)$ \\
\hline 90-day mortality (\%) & $3(0.3 \%)$ \\
\hline $\begin{array}{l}\text { Postoperative hospital-stay, days, median } \\
\text { (range) }\end{array}$ & $12(3-100)$ \\
\hline
\end{tabular}

$\%$ VC vital capacity, FEV1\% forced expiratory volume \% in one second, $R U$ right upper, $R M$ right middle, $R L$ right lower, $L U$ left upper, $L L$ left lower, RATS Robotassisted Thoracic Surgery, $C$ complete, VATS video-assisted thoracic surgery, $H$ hybrid, Part partial resection, Seg segmentectomy, Lob lobectomy, CW chest wall resection, Bilob bilobectomy, Pneumo pneumonectomy, $p$ pathological, $y$ yield to treatment, $A d$ adenocarcinoma, Sq squamous cell carcinoma, LCNEC large cell neuroendocrine carcinoma, AdSq adenosquamous cell carcinoma, Pleo pleomorphic carcinoma, Large large cell carcinoma, Carci carcinoid

the cause was not resolved due to sudden death after discharge. The median duration of postoperative hospital stay was 12 days.

\section{Univariate analysis}

The relationship between patient characteristics or operative factors and postoperative complications was 
Table 2 Relationship between patient characteristics or operative factors and postoperative complication

\begin{tabular}{ll}
\hline $\begin{array}{l}\text { Postoperative p value } \\
\text { complications }\end{array}$ & Present Absent
\end{tabular}

\section{Gender}

\section{Male}

Female

Age

$<75$ years

$\geq 75$ years

Smoking history

Present

Absent

Charlson Comorbidity index

$$
\geqq 3
$$$$
<3
$$

Coexistence of Interstitial lung disease

\section{Present}

Absent

Coexistence of diabetes mellitus

Present

Absent

Coexistence of malignancy

\section{Present}

Absent

Coexistence of asthma

$$
\text { Present }
$$

Absent

Coexistence of arrhythmia or angina pectoris

Present

Absent

$\mathrm{FEV}_{1} \%$

$$
<70 \%
$$$$
\geq 70 \%
$$

Lobe

RU
RM
RL
LU
LL
Operative approach
C-VATS + RATS
H-VATS + Open
Operative procedure
Lobectomy or more
Sublobar resection

FEV1\% forced expiratory volume \% in one second, $R U$ right upper, $R M$ right middle, $R L$ right lower, $L U$ left upper, $L L$ left lower, RATS Robot-assisted Thoracic Surgery, $C$ complete, VATS video-assisted thoracic surgery, $H$ hybrid

\begin{tabular}{|c|c|c|c|}
\hline & \multicolumn{2}{|c|}{ Air leakage } & \multirow[t]{2}{*}{$\mathrm{p}$ value } \\
\hline & Present & Absent & \\
\hline \multicolumn{4}{|l|}{ Gender } \\
\hline Male & $88(15 \%)$ & $497(85 \%)$ & \multirow[t]{2}{*}{$<0.01$} \\
\hline Female & $24(7 \%)$ & 347 (94\%) & \\
\hline \multicolumn{4}{|l|}{ Age } \\
\hline$<75 y$ & $77(11 \%)$ & $622(89 \%)$ & \multirow[t]{2}{*}{0.26} \\
\hline$\geq 75 y$ & $35(14 \%)$ & $222(86 \%)$ & \\
\hline \multicolumn{4}{|l|}{ Smoking history } \\
\hline Present & $87(15 \%)$ & $508(85 \%)$ & \multirow[t]{2}{*}{$<0.01$} \\
\hline Absent & $25(7 \%)$ & $336(94 \%)$ & \\
\hline \multicolumn{4}{|c|}{ Coexistence of interstitial lung disease } \\
\hline Present & $0(0 \%)$ & $22(100 \%)$ & \multirow[t]{2}{*}{0.08} \\
\hline Absent & $112(12 \%)$ & $822(88 \%)$ & \\
\hline \multicolumn{4}{|c|}{ Coexistence of diabetes mellitus } \\
\hline Present & $18(13 \%)$ & $118(87 \%)$ & \multirow[t]{2}{*}{0.55} \\
\hline Absent & $94(11 \%)$ & $726(89 \%)$ & \\
\hline \multicolumn{4}{|c|}{ Coexistence of malignancy } \\
\hline Present & $21(13 \%)$ & $140(87 \%)$ & \multirow[t]{2}{*}{0.56} \\
\hline Absent & $91(12 \%)$ & $704(88 \%)$ & \\
\hline \multicolumn{4}{|l|}{ Coexistence of asthma } \\
\hline Present & $3(10 \%)$ & $25(90 \%)$ & \multirow[t]{2}{*}{0.86} \\
\hline Absent & $109(12 \%)$ & $819(88 \%)$ & \\
\hline \multicolumn{4}{|c|}{$\begin{array}{l}\text { Coexistence of arrhythmia or angina } \\
\text { pectoris }\end{array}$} \\
\hline Present & $11(11 \%)$ & 87 (89\%) & \multirow[t]{2}{*}{0.87} \\
\hline Absent & $101(12 \%)$ & 757 (88\%) & \\
\hline \multicolumn{4}{|l|}{$\mathrm{FEV}_{1} \%$} \\
\hline$<70 \%$ & $52(16 \%)$ & $281(84 \%)$ & \multirow[t]{2}{*}{$<0.01$} \\
\hline$\geq 70 \%$ & $60(10 \%)$ & $563(90 \%)$ & \\
\hline \multicolumn{4}{|l|}{ Lobe } \\
\hline $\mathrm{RU}$ & $33(11 \%)$ & $256(89 \%)$ & \multirow[t]{5}{*}{0.18} \\
\hline RM & $4(7 \%)$ & $54(93 \%)$ & \\
\hline$R L$ & $28(12 \%)$ & $203(88 \%)$ & \\
\hline LU & $34(15 \%)$ & $186(85 \%)$ & \\
\hline $\mathrm{LL}$ & $13(8 \%)$ & 145 (92\%) & \\
\hline \multicolumn{4}{|l|}{ Operative approach } \\
\hline C-VATS + RATS & $51(15 \%)$ & $290(85 \%)$ & \multirow[t]{2}{*}{0.02} \\
\hline H-VATS + Open & $61(10 \%)$ & $554(90 \%)$ & \\
\hline \multicolumn{4}{|l|}{ Operative procedure } \\
\hline Lobectomy or more & $87(12 \%)$ & $622(88 \%)$ & \multirow[t]{2}{*}{0.36} \\
\hline Sublobar resection & $25(10 \%)$ & $222(90 \%)$ & \\
\hline
\end{tabular}

Table 3 Relationship between patient characteristics or operative factors and postoperative air leakage

FEV $1 \%$ forced expiratory volume \% in one second, $R U$ right upper, $R M$ right middle, $R L$ right lower, $L U$ left upper, $L L$ left lower, $C$ complete, VATS videoassisted thoracic surgery, RATS Robot-assisted Thoracic Surgery, $H$ hybrid

analyzed (Table 2). Postoperative complications were more likely to be associated with male sex $(\mathrm{p}<0.01)$, smoking history $(\mathrm{p}<0.01)$, coexistence of asthma 
$(\mathrm{p}=0.01)$, low $\mathrm{FEV}_{1} \%(\mathrm{p}<0.01)$, and lobectomy or greater resection $(\mathrm{p}<0.02)$. The results of the relationship between patient characteristics or operative factors and postoperative air leakage are presented in Table 3 . Postoperative air leakage was more likely to be associated with male sex $(\mathrm{p}<0.01)$, smoking history $(\mathrm{p}<0.01)$, coexistence of asthma $(\mathrm{p}<0.01)$, low $\mathrm{FEV}_{1} \%(\mathrm{p}<0.01)$, and C-VATS and RATS $(p=0.02)$. The relationship between patient characteristics or operative factors and postoperative atelectasis or pneumonia was analyzed and the results are presented in Table 4. Postoperative atelectasis or pneumonia was more likely to be associated with male sex $(\mathrm{p}=0.01)$, smoking history $(\mathrm{p}<0.01)$, coexistence of asthma $(\mathrm{p}<0.01)$, and low $\mathrm{FEV}_{1} \%(\mathrm{p}=0.03)$. The relationship between patient characteristics or operative factors and postoperative arrhythmia was analyzed and the results are presented in Table 5. Postoperative arrhythmia was more likely to be associated with H-VATS or thoracotomy $(\mathrm{p}=0.02)$ and with lobectomy or greater resection $(p<0.01)$. Significant risk factors for other postoperative complications could not be assessed due to small number of patients with these complications.

\section{Multivariate analysis}

The multivariate analyses of risk factors for postoperative complications are presented in Table 6. Male sex (odds ratio [OR]: 1.73, 95\% confidence interval $[\mathrm{CI}] 1.09-2.75$, $\mathrm{p}=0.01$ ), coexistence of asthma (OR 2.68, 95\% CI 1.196.02, $\mathrm{p}=0.01$ ), low $\mathrm{FEV}_{1} \%$ (OR 1.41, 95\% CI 1.02-1.95; $\mathrm{p}=0.03$ ), and lobectomy or greater resection (OR 2.47, 95\% CI 1.66-3.68, p <0.01) were identified as significant risk factors for postoperative complications. Results of the multivariate analyses of risk factors for postoperative air leakage, atelectasis, pneumonia, and arrhythmia are presented in Table 7. Male sex (OR 1.98, 95\% CI 1.03$3.81, \mathrm{p}=0.03$ ) and C-VATS and RATS (OR 1.64, 95\% CI $1.09-2.45, \mathrm{p}=0.01$ ) were identified as significant risk factors for postoperative air leakage. Coexistence of asthma (OR 9.97, 95\% CI 3.66-27.38, $\mathrm{p}<0.01$ ) was identified as a significant risk factor for postoperative atelectasis or pneumonia. Lobectomy or greater resection (OR 19.71, 95\% CI 2.70-143.57, p<0.01) was identified as a significant risk factor for postoperative arrhythmia.

\section{Discussion}

In the present study, we analyzed the risk factors for postoperative complications in patients who underwent pulmonary resection for NSCLC. Several factors such as age, smoking history, Charlson comorbidity index, operative approach, and the type of operative procedure have been reported as risk factors for postoperative complications in NSCLC patients who had undergone pulmonary resection $[5,20,21]$. In the present study, although
Table 4 Relationship between patient characteristics or operative factors and postoperative atelectasis or pneumonia

\begin{tabular}{|c|c|c|c|}
\hline & \multicolumn{2}{|c|}{$\begin{array}{l}\text { Atelectasis or } \\
\text { pneumonia }\end{array}$} & \multirow[t]{2}{*}{$\mathrm{p}$ value } \\
\hline & Present & Absent & \\
\hline \multicolumn{4}{|l|}{ Gender } \\
\hline Male & $37(6 \%)$ & $548(94 \%)$ & \multirow[t]{2}{*}{0.01} \\
\hline Female & $10(3 \%)$ & $361(97 \%)$ & \\
\hline \multicolumn{4}{|l|}{ Age } \\
\hline$<75$ years & $31(4 \%)$ & $668(96 \%)$ & \multirow[t]{2}{*}{0.25} \\
\hline$\geq 75$ years & $16(6 \%)$ & $241(94 \%)$ & \\
\hline \multicolumn{4}{|l|}{ Smoking history } \\
\hline Present & $39(6 \%)$ & $556(94 \%)$ & \multirow[t]{2}{*}{$<0.01$} \\
\hline Absent & $8(2 \%)$ & $353(98 \%)$ & \\
\hline \multicolumn{4}{|l|}{ Coexistence of ILD } \\
\hline Present & $2(9 \%)$ & $20(91 \%)$ & \multirow[t]{2}{*}{0.35} \\
\hline Absent & $45(5 \%)$ & $889(95 \%)$ & \\
\hline \multicolumn{4}{|c|}{ Coexistence of diabetes mellitus } \\
\hline Present & $6(4 \%)$ & $130(96 \%)$ & \multirow[t]{2}{*}{0.76} \\
\hline Absent & $41(5 \%)$ & 779 (95\%) & \\
\hline \multicolumn{4}{|c|}{ Coexistence of malignancy } \\
\hline Present & $8(5 \%)$ & $153(95 \%)$ & \multirow[t]{2}{*}{0.97} \\
\hline Absent & $39(5 \%)$ & $756(95 \%)$ & \\
\hline \multicolumn{4}{|l|}{ Coexistence of asthma } \\
\hline Present & $7(25 \%)$ & $21(75 \%)$ & \multirow[t]{2}{*}{$<0.01$} \\
\hline Absent & $40(4 \%)$ & $888(96 \%)$ & \\
\hline \multicolumn{4}{|l|}{$\mathrm{FEV}_{1} \%$} \\
\hline$<70 \%$ & $23(7 \%)$ & $310(93 \%)$ & \multirow[t]{2}{*}{0.03} \\
\hline$\geq 70 \%$ & $24(4 \%)$ & $599(96 \%)$ & \\
\hline \multicolumn{4}{|c|}{$\begin{array}{l}\text { Coexistence of arrhythmia or angina } \\
\text { pectoris }\end{array}$} \\
\hline Present & $8(8 \%)$ & $90(92 \%)$ & \multirow[t]{2}{*}{0.11} \\
\hline Absent & $39(5 \%)$ & $819(95 \%)$ & \\
\hline \multicolumn{4}{|l|}{ Lobe } \\
\hline $\mathrm{RU}$ & $18(6 \%)$ & $271(94 \%)$ & \multirow[t]{5}{*}{0.23} \\
\hline RM & $2(3 \%)$ & $56(97 \%)$ & \\
\hline $\mathrm{RL}$ & $10(4 \%)$ & $221(96 \%)$ & \\
\hline LU & $14(6 \%)$ & 206 (94\%) & \\
\hline LL & $3(2 \%)$ & 155 (98\%) & \\
\hline \multicolumn{4}{|l|}{ Operative approach } \\
\hline C-VATS + RATS & $12(4 \%)$ & $329(96 \%)$ & \multirow[t]{2}{*}{0.13} \\
\hline H-VATS + Open & $35(6 \%)$ & $580(94 \%)$ & \\
\hline \multicolumn{4}{|l|}{ Operative procedure } \\
\hline Lobectomy or more & $38(5 \%)$ & $671(95 \%)$ & \multirow[t]{2}{*}{0.28} \\
\hline Sublobar resection & $9(4 \%)$ & $238(96 \%)$ & \\
\hline
\end{tabular}

FEV $1 \%$ forced expiratory volume \% in one second, $R U$ right upper, $R M$ right middle, RL right lower, LU left upper, LL left lower, C complete, VATS videoassisted thoracic surgery, RATS Robot-assisted Thoracic Surgery, $H$ hybrid

Charlson comorbidity index was not significant risk factor for postoperative complications, sex, coexistence of asthma, low $\mathrm{FEV}_{1} \%$, and the type of operative procedure 
Table 5 Relationship between patient characteristics or operative factors and postoperative arrhythmia

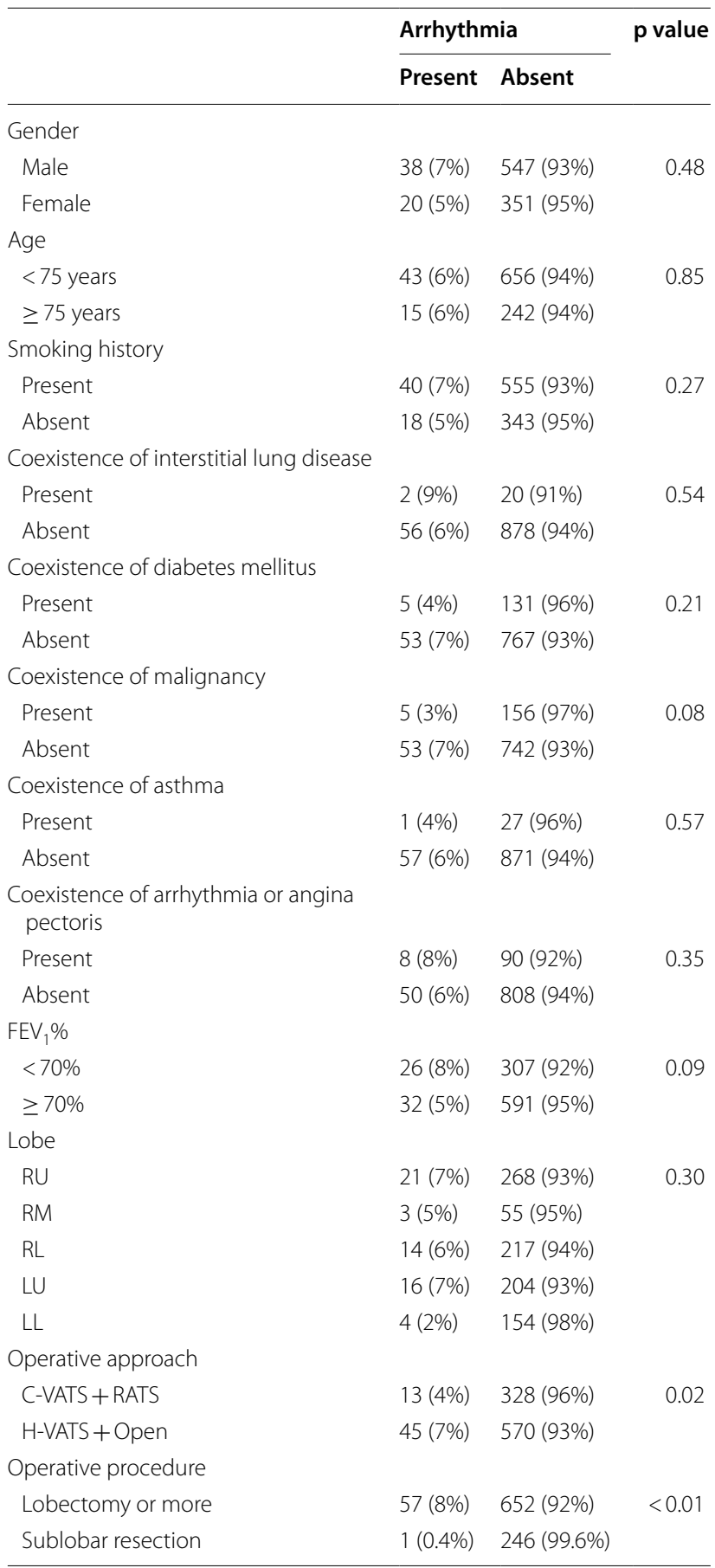

FEV1\% forced expiratory volume \% in one second, $R U$ right upper, $R M$ right middle, $R L$ right lower, $L U$ left upper, $L L$ left lower, $C$ complete, VATS videoassisted thoracic surgery, RATS Robot-assisted Thoracic Surgery, $H$ hybrid

were significant risk factors for postoperative complications. Furthermore, although the VATS approach has been reported to be less invasive than thoracotomy [1114], it has not been clarified whether it reduces postoperative complications in the present study.
Table 6 Multivariate analysis of risk factors for postoperative complications

\begin{tabular}{lccc}
\hline Risk factors & $p$ & OR & $\mathbf{9 5 \% ~ C l}$ \\
\hline $\begin{array}{l}\text { Gender } \\
\text { Male }\end{array}$ & 0.01 & 1.73 & $1.09-2.75$ \\
$\begin{array}{l}\text { Smoking history } \\
\text { Present }\end{array}$ & 0.08 & 1.50 & $0.94-2.40$ \\
$\begin{array}{l}\text { Asthma } \\
\quad \text { Present }\end{array}$ & 0.01 & 2.68 & $1.19-6.02$ \\
$\begin{array}{l}\text { FEV } \\
\text { 1 } \%\end{array}$ & 0.03 & 1.41 & $1.02-1.95$ \\
$\quad \begin{array}{l}\text { Operative procedure } \\
\text { Lobectomy or more }\end{array}$ & $<0.01$ & 2.47 & $1.66-3.68$ \\
\hline
\end{tabular}

O.R. odds ratio, $\mathrm{Cl}$ confidence interval, $F E V 1 \%$ forced expiratory volume $\%$ in one second

Postoperative air leakage is the most common complication after pulmonary resection, with a reported incident rate of $15-18 \%$ [22]. Although patient factors such as emphysematous lung or large parenchymal resection are considered to increase the risk of air leakage [23], male sex and C-VATS or RATS approach were significant risk factors for postoperative air leakage in the present study. Although the VATS or the RATS approach could provide a good field of view through the camera monitor, it is possible that air leakage was missed due to improper use of these systems in the initial days of their use.

Postoperative pulmonary complications are also common after pulmonary resection. And previous studies have reported an incidence rate of 6-29\% [6-9, 20, $23,24]$. In these reports, age, smoking history, chronic obstructive pulmonary disease, and thoracotomy have been reported as risk factors for postoperative pulmonary complications. In the present study, coexistence of asthma was a significant risk factor for postoperative atelectasis or pneumonia. Since asthma tends to produce mucus, it can lead to the development of postoperative atelectasis or pneumonia due to mucus plugging. However, male sex, smoking history, and low $\mathrm{FEV}_{1} \%$ were significantly associated with postoperative atelectasis or pneumonia in the univariate analysis. Thus, these factors might also be important risk factors for the development of postoperative pulmonary complications.

Atrial fibrillation is the most common type of postoperative arrhythmia in patients who have undergone pulmonary resection, with a reported incidence rate of $9-19 \%$ [25-28]. Although the mechanism of atrial fibrillation after non-cardiac thoracic surgery is unknown, several factors including male sex, age, amount of lung resection, previous episode of congestive heart failure, prior arrhythmia, and neoadjuvant chemotherapy were reported as the risk 
Table 7 Multivariate analysis of risk factors for postoperative complications

\begin{tabular}{|c|c|c|c|c|c|}
\hline Postoperative complications & Risk factors & & $p$ & O.R & $95 \% \mathrm{Cl}$ \\
\hline \multirow[t]{4}{*}{ Air leakage } & Gender & Male & 0.03 & 1.98 & $1.03-3.81$ \\
\hline & Smoking history & Present & 0.45 & 1.28 & $0.66-2.47$ \\
\hline & $\mathrm{FEV}_{1} \%$ & $<70 \%$ & 0.15 & 1.35 & $0.88-2.07$ \\
\hline & Operative approach & C-VATS + RATS & 0.01 & 1.64 & $1.09-2.45$ \\
\hline \multirow[t]{4}{*}{ Atelectasis or pneumonia } & Gender & Male & 0.21 & 1.85 & $0.69-4.99$ \\
\hline & Smoking history & Present & 0.14 & 2.14 & $0.77-5.95$ \\
\hline & Asthma & Present & $<0.01$ & 9.97 & $3.66-27.38$ \\
\hline & $\mathrm{FEV}_{1} \%$ & $<70 \%$ & 0.65 & 1.15 & $0.61-2.16$ \\
\hline \multirow[t]{2}{*}{ Arrhythmia } & Operative approach & C-VATS + RATS & 0.15 & 0.63 & $0.33-1.19$ \\
\hline & Operative procedure & Lobectomy or more & $<0.01$ & 19.71 & $2.70-143.57$ \\
\hline
\end{tabular}

$O . R$. odds ratio, Cl confidence interval, FEV1\% forced expiratory volume \% in one second, C complete, VATS video-assisted thoracic surgery, RATS Robot-assisted Thoracic Surgery

factors for postoperative arrhythmia [25-28]. In the present study, the incidence rate of postoperative arrhythmia was $6.1 \%$ and the type of operative procedure (lobectomy or greater resection) was a significant risk factor for postoperative arrhythmia. It is suggested that the risk of postoperative arrhythmia might be related to the amount of lung resection.

Reportedly, VATS is associated with less pain, less reduction in the inflammatory immune response, and maintenance of postoperative respiratory function when compared with thoracotomy. Therefore, VATS is considered a less invasive procedure [11-14]. On the other hand, it was reported that VATS dose not reduce the incidence rate of postoperative atrial fibrillation after pulmonary lobectomy [29]. It was suggested that autonomic denervation and stress-mediated neurohumoral mechanisms resulting from anatomic pulmonary resection, and not an incision-related effect. In the univariate analysis, the incidence rate of postoperative arrhythmia was significantly higher in patients who underwent H-VATS or thoracotomy. However, the operative approach was not a significant risk factor in the multivariate analysis in the present study. Although C-VATS or RATS are less invasive, the operative approach might not reduce the incidence rate of postoperative arrhythmia.

The present study has several limitations. The study had a retrospective design and there was a possibility of unobserved cofounding and selection bias. Another limitation is that the present study was performed at a single institution.

\section{Conclusions}

Our findings analyzed the risk factors for postoperative complications in patients who underwent pulmonary resection for NSCLC. Male sex, coexistence of asthma, low $\mathrm{FEV}_{1} \%$, and the type of operative procedure were significant risk factors for postoperative complications. Risk factors varied according to postoperative complications. Male sex and C-VATS or RATS approach were significant risk factors for postoperative air leakage. Coexistence of asthma was a significant risk factor for postoperative atelectasis or pneumonia. The type of operative procedure (lobectomy or greater resection) was a significant risk factor for postoperative arrhythmia. Because there is no specific risk score for the occurrence of postoperative complications after pulmonary resection, and further studies are needed. In addition, further analysis of risk factors involved in the development of individual complications after pulmonary resection is considered to be necessary.

\section{Abbreviations}

NSCLC: Non-small cell lung cancer; VATS: Video-assisted thoracic surgery; \%VC: Vital capacity; FEV1\%: Forced expiratory volume \% in one second, robotassisted thoracic surgery.

\section{Acknowledgements}

Not applicable.

\section{Authors' contributions}

NM performed the research, collected and analyzed the data and wrote the paper. $\mathrm{MI}, \mathrm{SI}, \mathrm{Yl}$, and $\mathrm{KU}$ contributed to sample collection. $\mathrm{HU}$ contributed to supervision of this study and revision of the manuscript. All authors have read and approved the manuscript, and ensure that this is the case.

\section{Funding}

This study has not been funded.

\section{Availability of data and materials}

The datasets generated and/or analyzed during the current study are not publicly available due to [our institutional restrictions e.g. them containing information that could compromise research participant privacy/consent], but are available from the corresponding author on reasonable request. 


\section{Declarations}

\section{Ethics approval and consent to participate}

The present study was conducted in accordance with the amended Declaration of Helsinki. The Institutional Review Boards of Kanazawa Medical University approved the protocol (Approval Number: 1392), and written informed consent was obtained from all of the patients.

\section{Consent for publication}

Not applicable.

\section{Competing interests}

The authors declare that they have no competing interests.

Received: 24 March 2021 Accepted: 11 June 2021

Published online: 14 July 2021

\section{References}

1. Siegel RL, Miller KD, Jemal A. Cancer statistics, 2018. CA Cancer J Clin. 2018:68:7-30

2. Rueth NM, Andrade RS. IS VATS lobectomy better: perioperatively, biologically and oncologically? Ann Thorac Surg. 2010;89:S2107-11.

3. Boffa DJ, Allen MS, Grab JD, Gaissert HA, Harpole DH, Wright CD. Data from The Society of Thoracic Surgeons General Thoracic Surgery database: the surgical management of primary lung tumors. J Thorac Cardiovasc Surg. 2008;135:247-54

4. Allen MS, Darling GE, Pechet TTV, Mitchell JD, Herndon JE II, Landreneau $\mathrm{RJ}$, et al. Morbidity and mortality of major pulmonary resections in patients with early-stage lung cancer: initial results of the randomized, prospective ACOSOG Z0030 trial. Ann Thoac Surg. 2006;81:1013-20.

5. Berry MF, Hanna J, Tong BC, Burfeind WR, Harpole DH, D'Amico TA, et al. Risk factors for morbidity after lobectomy for lung cancer in eldery patients. Ann Thorac Surg. 2009;88:1093-9.

6. Jung R, He S, Dai H, Lin F, Ge W, Tao G, et al. Incidence and risk factors of postoperative pulmonary complications after thoracic surgery for early non-small cell lung cancer. Int J Clin Exp Med. 2018;11(1):285-94.

7. Agostini P, Lugg ST, Adams K, Smith T, Kalkat MS, Rajesh PB, et al. Risk factors and short-term outcomes of postoperative pulmonary complications after VATS lobectomy. J Cardiothorac Surg. 2018;13:28.

8. Lee JY, Jin SM, Lee CH, Lee BJ, Kang CH, Yim JJ, et al. Risk factors of postoperative pneumonia after lung cancer surgery. J Korean Med Sci. 2011:26:979-84.

9. Agostini P, Cieslik H, Rathinam S, Bishay E, Kalkat MS, Rajesh PB, et al. Postoperative pulmonary complications following thoracic surgery: are there any modifiable risk factors? Thorax. 2010;65:815-8.

10. Stolz AJ, Schutzner J, Lischke R, Simonek J, Harustiak T, Pafko P. Predictors of atelectasis after pulmonary lobectomy. Surg Today. 2008;38:987-92.

11. Mckenna RJ Jr, Houck W, Fuller CB. Video-assisted thoracic surgery lobectomy: experience with 1100 cases. Ann Thorac Surg. 2006;81:421-6.

12. Flores RM, Park BJ, Dycoco J, Aronova A, Hirth Y, Rizk NP, et al. Lobectomy by video-assisted surgery (VATS) versus thoracotomy for lung cancer. $J$ Thorac Cardiovasc Surg. 2009;138:11-8.

13. Whitson BA, Groth SS, Duval SJ, Swanson SJ, Maddaus MA. Surgery for early-stage non-small cell lung cancer: a systematic review of the video-assisted thoracoscopic surgery versus thoracotomy approaches to lobectomy. Ann Thorac Surg. 2008;86:2008-18.

14. Sakuraba M, Miyamoto H, Oh S, Shiomi K, Sonobe S, Takahashi N, et al. Video-assisted thoracoscopic lobectomy vs. conventional lobectomy via open thoracotomy in patients with clinical stage IA non-small cell lung carcinoma. Interact Cardiovasc Thorac Surg. 2007;6:614-7.

15. Charlson ME, Pompei $\mathrm{P}$, Ales $\mathrm{KL}$, et al. A new method of classifying prognostic comorbidity in longitudinal studies: development and validation. J Choric Dis. 1987:40:373-83.

16. Brinkman GL, Coates EO. The effect of bronchitis, smoking, and occupation on ventilation. Am Rev Respir Dis. 1963;87:684-93.

17. Katayama H, Kurokawa Y, Nakamura K, Ito H, Kanemitsu Y, Masuda N, et al. Extended Clavien-Dindo classification of surgical complications: Japan Clinical Oncology Group postoperative complications criteria. Surg Today. 2016:46:668-85.

18. Clavien PA, Sanabria JR, Strasberg SM. Proposed classification of complications of surgery with examples of utility in cholecystectomy. Surgery. 1992:111:518-26.

19. Dindo D, Demartines N, Clavien PA. Classification of surgical complications: a new proposal with evaluation in a cohot of 6336 patients and results of a survey. Ann Surg. 2004;240:205-13.

20. Pei G, Zhou S, Han Y, Liu Z, Xu S. Risk factors for postoperative complications after lung resection for non-small cell lung cancer in elderly patients at a single institution in China. J Thorac Dis. 2014;6(9):1230-8.

21. Dogru MV, Sezen CB, Aker C, Girgin O, Kilimci U, Erduhan S, et al. Evaluation of factors affecting morbidity and mortality in pneumonectomy patients. Ata Chir Belg. 2020;16:1-7.

22. Rice TW, Kirby TJ. Prolonged air leakage. Chest Surg Clin N Am. 1992:2:802-11.

23. Ziarnik E, Grogan EL. Post-lobectomy early complications. Thorac Surg Clin. 2015:25:355-64

24. Villenneuve PJ. Interventions to avoid pulmonary complications after lung cancer resection. J Thorac Dis. 2018;10:S3781-3788.

25. Roselli EE, Murthy SC, Rice TW, Houghtaling PL, Pierce CD, Karchme DP, et al. Atrial fibrillation complicating lung cancer resection. J Thorac Cardiovasc Surg. 2005;130:438-44.

26. Asamura H, Naruke T, Tsuchiya R, Goya T, Kondo H, Suemasu K. What are the risk factors for arrhythmias after thoracic operations? A retrospective multivariate analysis of 267 consecutive thoracic operations. J Thorac Cardiovasc Surg. 1993;106:1104-10.

27. Onaitis M, Damico T, Zhao Y, Obrien S, Harpole D. Risk factors for atrial fibrillation after lung cancer surgery: analysis of The Society of Thoracic Surgeons General Thoracic Surgery Database. Ann Thorac Surg. 2010;90:368-74.

28. Brunelli A, Rocco G, Szanto Z, Thomas P, Falcoz PE. Morbidity and mortality of lobectomy or pneumonectomy after neoadjuvant treatment: an analysis from the ESTS database. Eur J Cardiothorac Surg. 2020;57:740-6.

29. Park BJ, Zhang H, Rusch VW, Amar D. Video-assisted thoracic surgery does not reduce the incidence of postoperative atrial fibrillation after pulmonary lobectomy. J Thorac Cardiovasc Surg. 2007;133:775-9.

\section{Publisher's Note}

Springer Nature remains neutral with regard to jurisdictional claims in published maps and institutional affiliations. 